\title{
DUCTILITY OF UNCONFINED MASONRY SHEAR WALLS
}

\author{
M.J.N. Priestley*
}

SUMMARY:

Relationships defining the ductility capacity of rectangular unconfined masonry shear walls are developed. The limit to ductility is imposed by an ultimate strain of 0.0025 and the shape of a recently proposed stress-strain curve for unconfined masonry. Results are presented in the form of simple charts, suitable for design use, giving displacement ductility capacity in terms of material strengths, reinforcement ratios, axial load and aspect ratio.

Options open to the designer when the charts indicate insufficient ductility is available for the design seismic base shear are discussed. A method for extending the applicability of the charts to non-rectangular sections is suggested.

\section{INTRODUCTION:}

Seismic design philosophy for masonry shear walls, incorporated in the N.Z. Loadings code ${ }^{1}$ and the draft masonry design code ${ }^{2}$ implies the ability of masonry shear walls to exhibit significant ductility. The basic seismic coefficient $C$ in the loadings code has been derived from smoothed elastic response spectra for design level seismic attack by approximately dividing the $10 \%$ damping curves by a factor of 4 . The structural type factor $S$ proportionably increases the design lateral force levels, which, assuming the validity of the equal displacement principle, implies design to a displacement ductility factor of

$$
\mu=\frac{4}{S}
$$

For masonry structures, this design level of required ductility should not be further reduced as a result of the high materials factor, $M=1.2$, since this is intended to compensate for reduced energy absorption in the load-deflection hysteresis loops of masonry structures when compared with equivalent concrete structures. Similarly, $\mu$ should not be reduced for high values of the Importance factor $I$ or Risk factor $R$, since these are intended to provide increased assurance against failure where the importance of continued structural functionality is high, or consequences of damage are potentially hazardous.

Despite the implied level of displacement ductility given by Eq. 1 , it is very rare that a designer will attempt to calculate whether or not his structural elements can sustain the required level of ductility without either collapse or severe load degradation. In the design of reinforced concrete structures, detailed design rules for plastic hinge regions have been developed, and incorporated in the draft concrete design code ${ }^{3}$ which ensure the design level of ductility can be obtained, without requiring the designer to perform a ductility capacity

* Reader in Civil Engineering, University of Canterbury check. For columns and shear walls, the primary means of ensuring ductility is to provide lateral confining steel at close-spaced centres to effectively increase the ultimate concrete compression strain, and hence the ultimate curvature and ductility. The rules are conservative, intended to cope with the most critical conditions, and do not reflect the theoretical dependence of ductility capacity on such variables as element aspect ratio or flexural reinforcement content.

Although the same approach can be, at least in theory, adopted for masonry structures, confining reinforcement is difficult to provide, and can only 4 be incorporated within mortar beds 4 . For concrete masonry construction, this means spacing the confining steel at $200 \mathrm{~mm}$ centres, which reduces the efficiency of confinement and the support against compression bar buckling at high strains. It can, however, be shown that many masonry shear walls can develop the level of ductility implied by Eq. 1 without exceeding compression strains that can be sustained by unconfined masonry. Although the calculations are comparatively straightforward they are tedious. This paper develops the background to ductility calculations for masonry shear walls, presents results in a form suitable for the design office, and identifies the critical parameters affecting ductility.

\section{MASONRY STRESS-STRAIN CURVES:}

The available ductility of masonry walls is dependent, amongst other factors, on the ultimate compression strain, and general stress-strain characteristics of masonry compression. Recent testing of concrete masonry prisms ${ }^{4}$ has indicated that for normal weight concrete blocks, the unconfined stress-strain curve is similar to that for unconfined concrete, except that peak stress and crushing occur at lower strains. The tests indicated that peak stress occurred at a strain of approximately 0.0015 as a result of premature formation of vertical cracking of the concrete masonry face shells, caused by lateral expansion of the crushing mortar. This vertical splitting 
propogated into the grout core and caused a fairly steep falling branch. Despite the ability of the masonry to support some load up to a strain as high as 0.005 , an effective ultimate strain of 0.0025 was recommended, because of the potential instability of the compression zone under combined axial force and shear, after formation of extensive vertical splitting. This value for the ultimate strain has been adopted by the draft masonry design code ${ }^{2}$.

Fig. I shows a theoretical curve for unconfined masonry, based on these tests, and obtained by modifying the ${ }_{5}$ Kent-Park curve for unconfined concrete ${ }^{5}$. The rising portion is defined by a parabola related to a strain of 0.002 and $a$ corresponding fictitious stress

$$
f_{m}^{\prime \prime}=\frac{f_{m}^{\prime}}{0.9375}
$$

which is effectively the ratio of predicted stresses at 0.0015 and 0.002 strain from the Kent-Park curve. The falling branch is obtained by shifting the Kent-Park curve to the left by a strain of 0.0005 . Thus the curve for unconfined masonry can be defined by the following equations:

$$
\begin{aligned}
& \varepsilon_{m} \leqslant 0.0015 \\
& f_{m}=\frac{f_{m}^{\prime}}{0.9375}\left[\frac{2 \varepsilon_{m}}{0.002}-\left(\frac{\varepsilon_{m}}{0.002}\right)^{2}\right]
\end{aligned}
$$

$$
\begin{aligned}
& 0.0015 \leqslant \varepsilon_{m} \leqslant 0.0025 \\
& f_{m}=f_{m}^{\prime}\left\{1-z_{m}\left(\varepsilon_{m}-0.0015\right)\right\}
\end{aligned}
$$

where

$$
\mathrm{z}_{\mathrm{m}}=\frac{0.5}{\frac{3+0.29 f_{m}^{\prime}}{145 f_{m}^{\prime}-1000}-0.002}
$$

The unconfined curve given by the above equations and shown in Figure 1 provided good agreement with measured stress-strain curves. Also shown in Figure 1 is a curve for concrete masonry prisms confined with $3 \mathrm{~mm}$ thick stainless steel plates within the mortar beds, and cut to the net shape of the masonry units with an allowance for pointing. The confining plates inhibited the vertical splitting failure mode, increased the strength, and resulted in a much flatter falling branch. A safe ultimate compression strain for masonry confined in this fashion is estimated to be $0.008^{4}$. Figure 2 shows typical failures of unconfined and confined masonry prisms.

It should be noted that the curves in Figure I have been obtained from testing normal weight concrete masonry prisms with rather high masonry unit strength.
Although the resulting shape of the stressstrain curve is taken as being applicable to all masonry strengths, further testing is required to explore the range of applicability, particularly for lightweight aggregate blockwork, and clay-brick masonry.

\section{DUCTILITY CAPACITY OF UNCONFINED WALLS :}

Figure 3 defines the nomenclature for analysis. The wall has sectional dimensions $l_{w} \times b$, and an effective height to the centre of seismic force $h_{e}$. Within the plastic hinge region the wall is subjected to axial load $\mathrm{N}_{\mathrm{u}}$, and distributed reinforcement $\mathrm{A}_{\mathrm{st}} \cdot$ Neutral axis positions at yield and ultimate are respectively $c_{e}$ and $c_{u}$ distance from the extreme compression fibre. Steel yield strength is $f_{y}$ and masonry crushing strength, $f_{m}^{\prime}$.

Figure 4 shows the idealised loaddeflection curve related to the height of the centre of seismic force. The displacement at the yield moment $M_{y}$ (first yield of extreme tension steel) is extrapolated from zero to the ultimate moment capacity $\mathrm{M}_{\mathrm{u}}$ to give yield displacement $\Delta_{\mathrm{Y}} \cdot \Delta_{\mathrm{u}}$ is ${ }^{\mathrm{u}}$ the displacement corresponding to an ultimate strain of 0.0025 . By definition, the ductility capacity of the wall is

$$
\mu=\frac{\Delta_{u}}{\Delta_{y}}
$$

\section{Conditions at First Yield -}

An expression for the neutral axis position can be obtained by integrating the masonry stress-strain curve, and equating the compression force in masonry and steel within the compression zone, to steel tensile force in the tension zone plus axial force $\mathrm{N}_{\mathrm{u}}$

Thus, in dimensionless form,

$$
\begin{aligned}
& 2\left(\frac{f_{m}^{\prime}}{0.9375 f_{y}} \cdot \frac{\varepsilon_{y}}{0.002}\right) k_{e}^{2}\left(1-\left(\frac{k_{e}}{1-k_{e}}\right) \frac{\varepsilon_{y}}{0.006}\right) \\
& +2\left(\rho+\frac{N_{u}}{b l_{w} f_{y}}\right) k_{e}-\left(\rho+\frac{2 N_{u}}{b l_{w} f_{y}}\right)=0 \\
& \text { where } \quad \rho=\frac{\mathrm{A}_{\mathrm{st}}}{\mathrm{b} l_{\mathrm{i}}} \text {, } \\
& k_{e}=\frac{c_{e}}{l_{w}} \\
& \text { and } \varepsilon_{y}=\frac{f_{y}}{E_{s}} \text { is the reinforcement }
\end{aligned}
$$

Eq. 7 can be solved for $k_{e}$ by successive approximation techniques. The yield moment can then be found by taking moments 


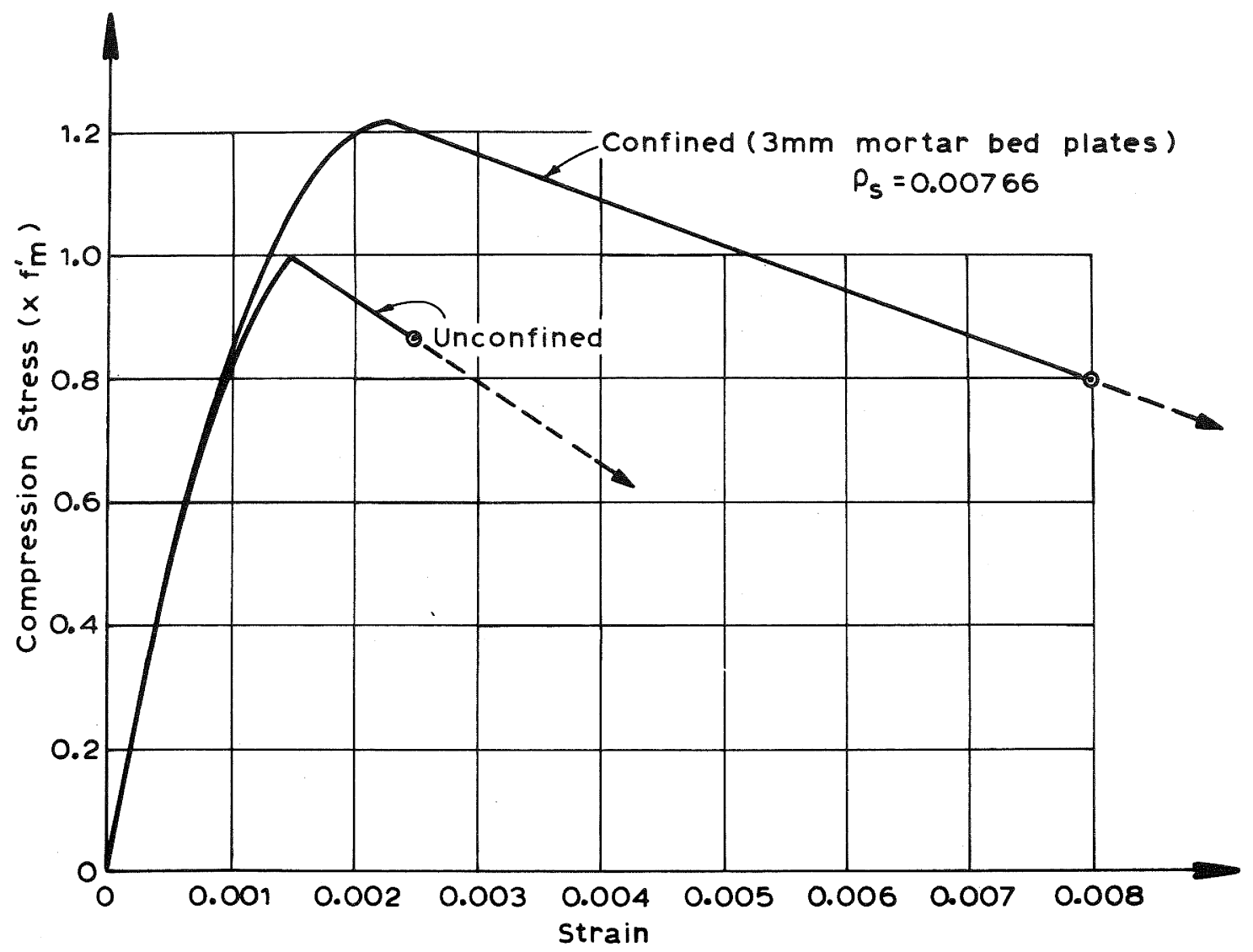

FIG. 1 - MASONRY STRESS - STRAIN CURVES (Plotted for $\mathrm{f}_{\mathrm{m}}^{\prime}=16 \mathrm{MPa}$ )

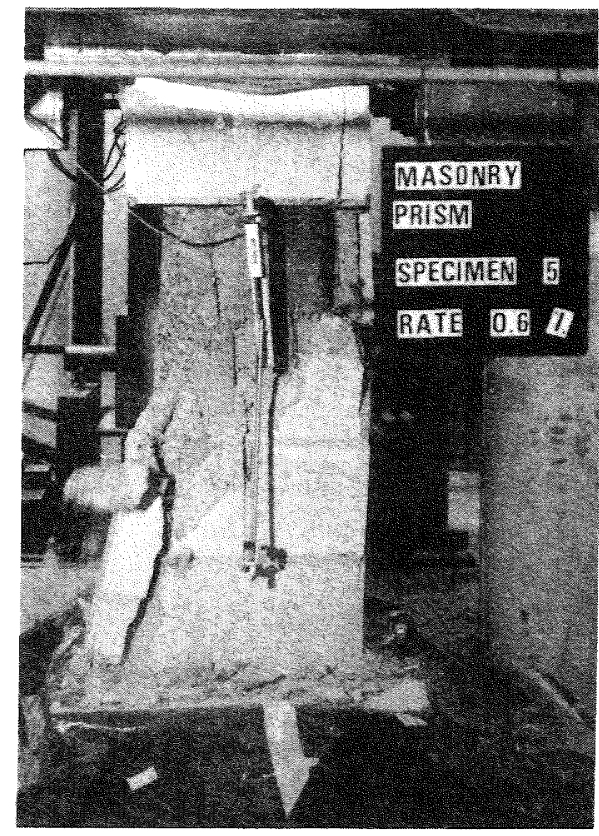

(a) Unconfined

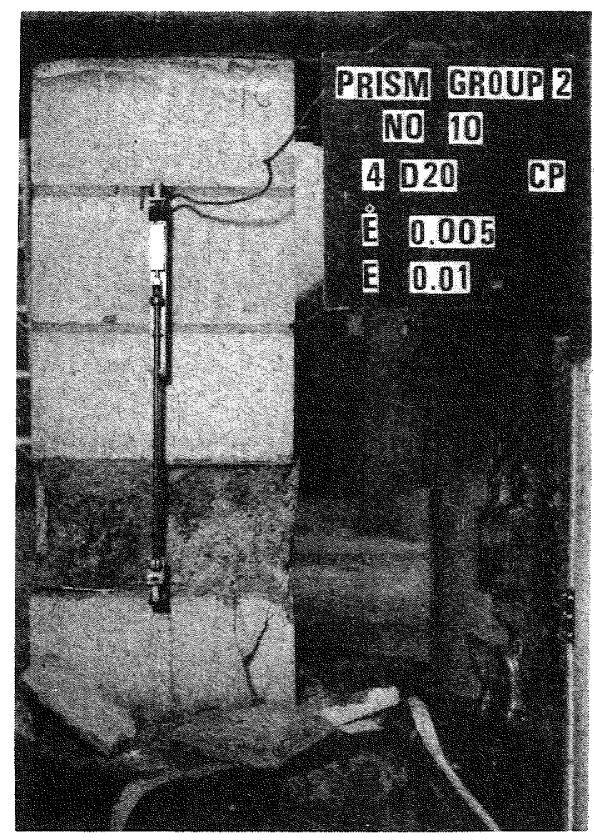

(b) Confined 

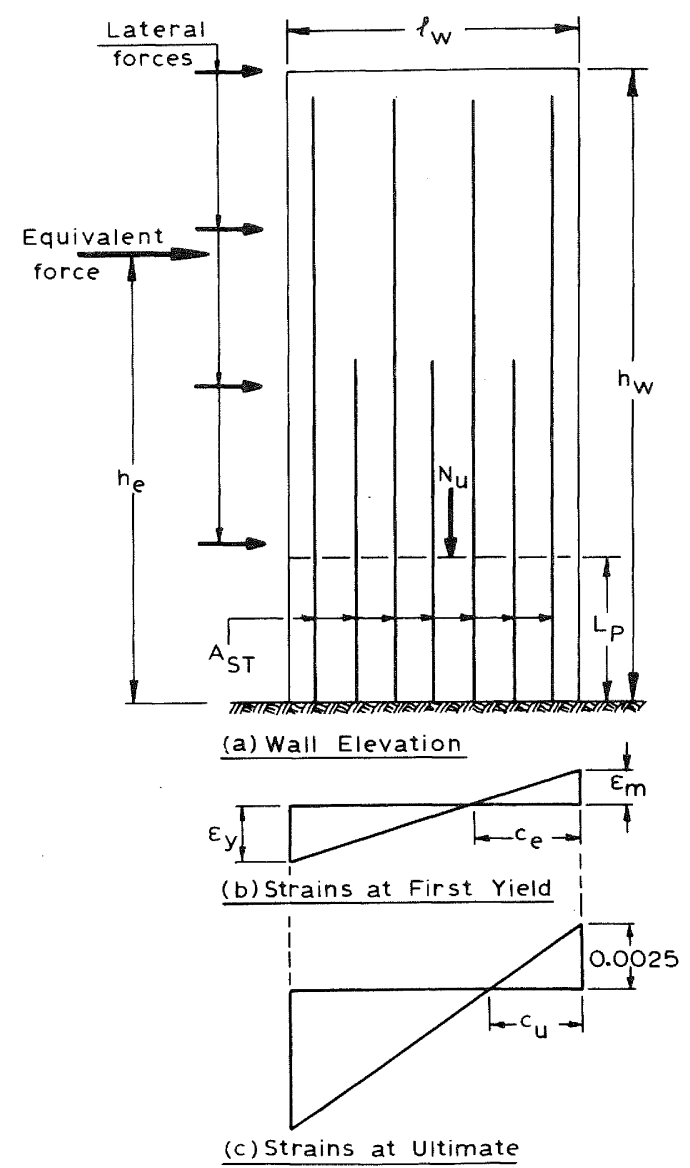

FIG 3. - NOMENCLATURE FOR DUCTILITY ANALYSIS

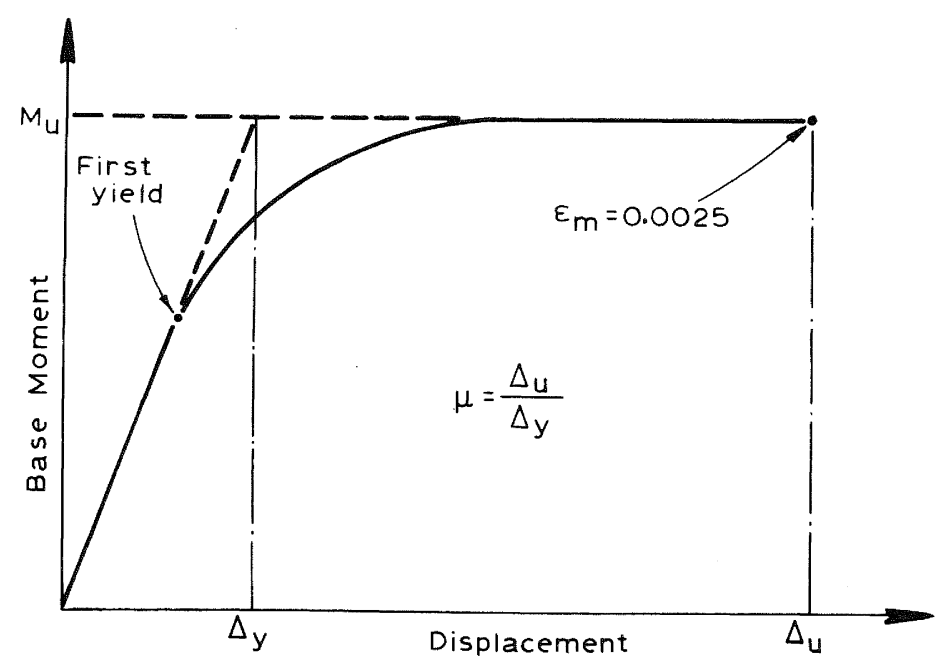

FIG. 4 - DISPLACEMENT DUCTILITY AT HEIGHT OF CENTRE OF SEISMIC FORCE. 
about the neutral axis. Again in dimensionless form:

$$
\begin{aligned}
m_{y}= & \frac{M_{y}}{b l_{w}{ }^{2} f_{y}}=\left(\frac{f_{m}^{\prime}}{0.9375 f_{y}}\right) k_{e}^{2} \cdot \frac{\varepsilon_{m}}{0.002} \cdot \\
& \left(\frac{2}{3}-\frac{\varepsilon_{m}}{0.008}\right)+\frac{k_{e}^{3}}{3\left(1-k_{e}\right)} \rho+\frac{\left(1-k_{e}\right)^{2}}{3} p \\
& +\frac{N_{u}}{b l_{w} f_{y}}\left(\frac{1}{2}-k_{e}\right)
\end{aligned}
$$

where

$$
\varepsilon_{m}=\left(\frac{k_{e}}{I-k_{e}}\right) \quad \varepsilon_{y} \begin{aligned}
& \text { is the extreme } \\
& \begin{array}{l}
\text { fibre compression } \\
\text { strain. }
\end{array}
\end{aligned}
$$

The curvature at first yield is

$$
\phi_{y}=\frac{\varepsilon_{y}}{\ell_{w}\left(1-k_{e}\right)}
$$

\section{Conditions at Ultimate -}

For simplicity it is assumed that all flexural reinforcement is at yield stress. The errors involved are small, since non-yielding reinforcement is close to the neutral axis, and are much less significant than other variations, such as length of plastic hinge. Using conventional ultimate strength theory, and equating compression force in masonry and steel to tension force plus axial load gives the neutral axis position as

$$
k_{u}=\frac{c_{u}}{l_{w}}=\frac{\left(\rho+\frac{N_{u}}{b_{l_{w}} f_{y}}\right)}{\left(0.7225 \frac{f_{m}^{\prime}}{f_{y}}+2 \rho\right)}
$$

and taking moments about the neutral axis, the dimensionless ultimate moment is

$$
\begin{aligned}
& m_{u}=\frac{{ }_{u}}{b l_{w}^{2} f_{y}}=0.415 \mathrm{k}^{2} u \frac{f_{m}^{\prime}}{f_{y}}+
\end{aligned}
$$

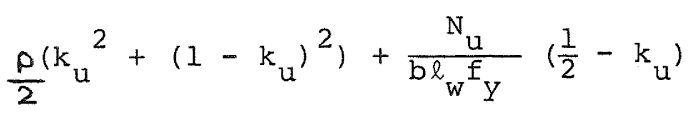

The ultimate curvature is

$$
\phi_{u}=\frac{0.0025}{k_{u} \cdot l_{w}}
$$

\section{Displacement Ductility -}

In Figure 5 two cases are considered: one with a rigid foundation (Figure $5 b$ ) and the other where the foundation is flexible, resulting in an increase to the yield displacement (Figure $5 \mathrm{c}$ ). In both cases, assuming elasto-plastic behaviour of the plastic hinge, all plastic displacement $\Delta p$ occurs in the hinge.
Consequently the ratio of ultimate displacement to yield displacement (i.e. displacement ductility) is less for the flexible foundation $\mathrm{case}^{6}$. First consider the rigid foundation case.

Extrapolating conditions at first yield to ultimate, and assuming a constant neutral axis position with height, the yield displacement is given by

$\Delta_{y}=\frac{m_{u}}{m_{y}} \cdot \frac{\phi_{y} h_{e}{ }^{2}}{3}$

Recent research ${ }^{7,8}$ supports the use of a plastic hinge length for ductility calculations that is equal to half the section length, regardless of aspect ratio, thus $L_{p}=\frac{l_{w}}{2}$. The plastic displacement is thus

$\Delta_{p}=\left(\phi_{u}-\frac{m_{u}}{m_{y}} \phi_{y}\right) \cdot \frac{l_{w}}{2}\left(h_{e}-\frac{l_{w}}{4}\right)$

giving the available ductility as

$\mu=1+\frac{\Delta_{p}}{\Delta_{y}}$

$=1+\frac{1.5}{A_{e}}\left(\frac{\phi_{u} m_{y}}{\phi_{y} \cdot m_{u}}-1\right)\left(1-\frac{1}{4 A_{e}}\right)$

where $A_{e}=\frac{h_{e}}{l_{w}}$
ratio.

Where the flexibility of the foundation is such that the yield displacement is increased to

$\Delta_{y}=\Delta_{f}+\Delta_{s}=C \cdot \Delta_{s}$

where $\Delta_{f}$ is the displacement resulting from foundation compliance and $\Delta_{s}$ is the structural component of displacement, then similar arguing to the above ${ }^{6}$ gives the available ductility as

$\mu_{C}=1+\frac{1.5}{C \cdot A_{e}}\left(\frac{\phi_{u} \cdot m_{y}}{\phi_{y} \cdot m_{u}}-1\right)\left(1-\frac{1}{4 A_{e}}\right)$

Note that $\mathrm{C}=1.0$ implies a rigid foundation.

Eqs. 7 to 12,15 and 17 are in a form suitable for a sensitivity analysis. A small computer program was written to solve for $\mu$ in terms of the following values of the effective variables.

Reinforcement yield strength $f_{y}=275,380 \mathrm{MPa}$

Masonry compression strength

$8 \mathrm{MPa} \leqslant f_{m}^{\prime} \leqslant 32 \mathrm{MPa}$

Flexural reinforcement ratio

$0.0007 \leqslant \rho \leqslant 0.0107$

Axial load level $0 \leqslant \frac{\mathrm{N}_{\mathrm{u}}}{\mathrm{bl}_{\mathrm{w}}} \leqslant 0.3 \mathrm{f}_{\mathrm{m}}^{\prime}$

Effective Aspect Ratio $0.5 \leqslant A_{e} \leqslant 7$. 


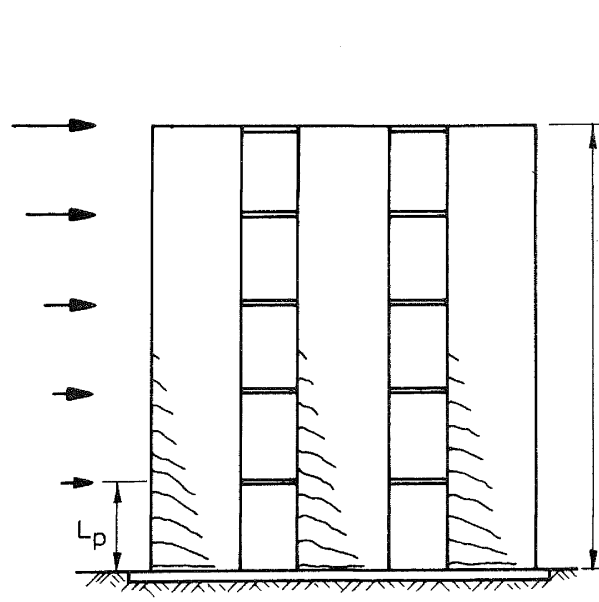

(a) Crack Pattern

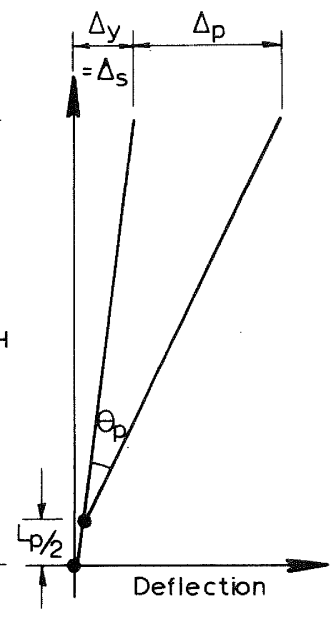

(b) Deflection Profiles. Rigid Foundation

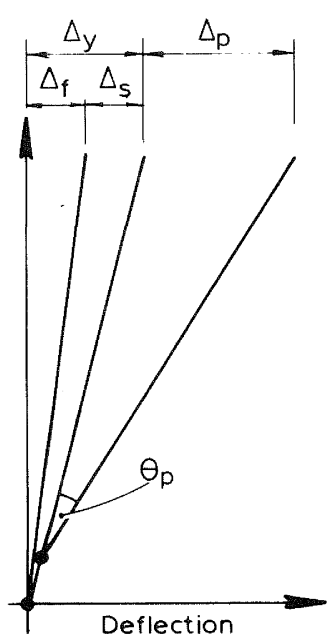

(c) Deflection Profiles, Flexible Foundation

FIG 5. - CANTILEVER SHEAR WALLS LINKED BY FLEXIBLE FLOOR SLABS

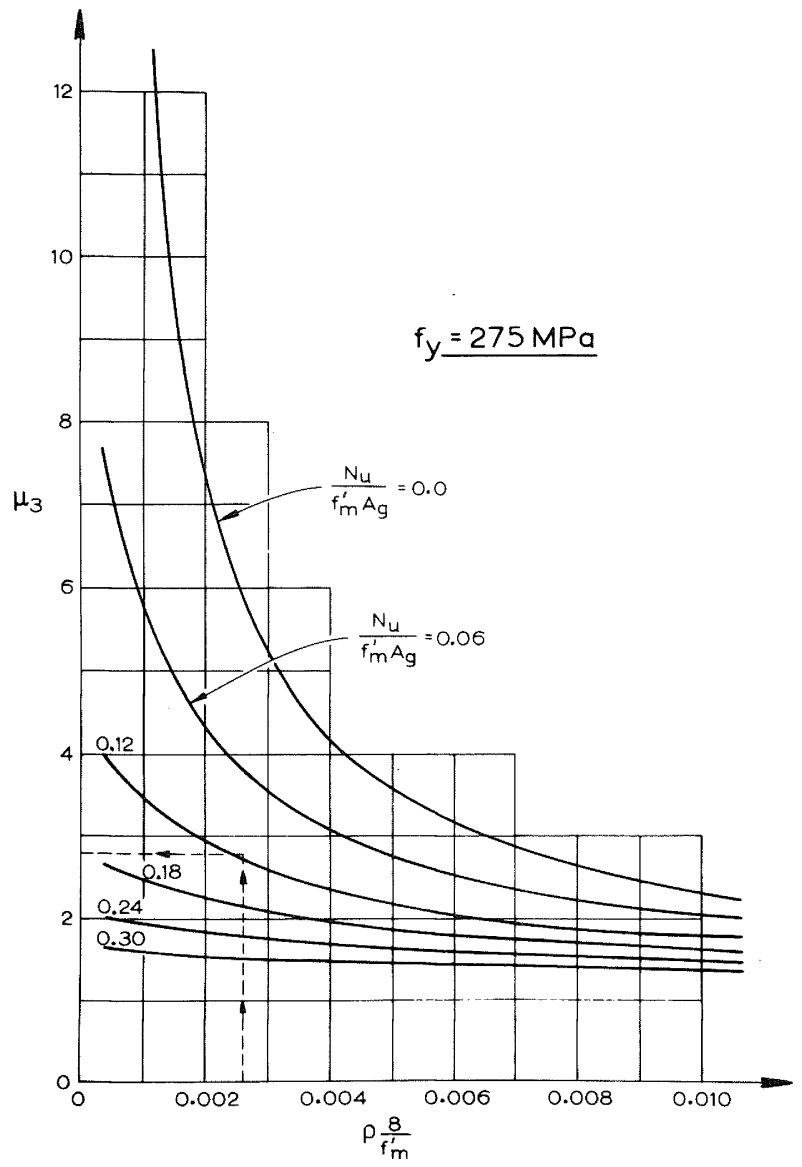

FIG 6. - DUCTILITY OF MASONRY W'ALLS FOR ASPECT RATIO $A_{T}=3(f y=275 \mathrm{MPa})$ 
It should be noted that $f_{m}^{\prime}=8 \mathrm{MPa}$ is the design strength for Grades $B$ and A masonry unless prisms are tested, and $\rho=0.0007$ is the minimum flexural reinforcement allowed by the draft masonry design code.

\section{RESULTS:}

Results of the computer sensitivity analysis are presented in Figures 6-8. Figures 6 and 7 give ductility factors for walls of true aspect ratio $A_{T}=3$ for $\mathrm{f}_{\mathrm{y}}=275 \mathrm{MPa}$ and $380 \mathrm{MPa}$. Figure 8 plots the correction factor for walls of true aspect ratios other than $\mathrm{A}_{\mathrm{T}}=3$. Note that in changing from the effective aspect ratios of Eqs. 15 and 16 to the true aspect ratios (i.e. $h_{w} / l_{w}$ ) of Figures 6-8 a uniform distribution of mass with height and an inverted triangle acceleration distribution has been assumed. Thus

$\mathrm{A}_{\mathrm{T}}=1.5 \mathrm{~A}_{\mathrm{e}}$

For structures where this approximation is too crude, the appropriate adjustment may be made after calculating the effective height.

It will be noted that it has been possible to express $\mu_{3}$ values for all rectangular walls with $f=275 \mathrm{MPa}$ or $E=380 \mathrm{MPa}$ on a single graph using the variables

$\frac{N_{u}}{f_{m}^{1} A_{g}}$, where $A_{g}=b l_{w}$. and $\rho \cdot \frac{8}{f_{m}^{\prime}}$.

Obvious trends apparent from Figures 6 and 7 are a dramatic decrease in ductility with increasing reinforcement ratio and axial load level, and an increase in ductility with increasing masonry compression strength. Increasing the steel yield strength also decreases ductility capacity.

The effect of foundation compliance can be directly obtained from Figures 6-8 using the relationship

$\frac{\mu-I}{\mu_{3}-I}=\frac{f\left(A_{T}\right)}{C}$

where $C$ is the foundation flexibility coefficient defined by Eq., 16, and $E\left(A_{T}\right)$ is the function of aspect ratio plotted in Figure 8.

\section{DISCUSSION OF RESULTS:}

Most structural masonry will be designed to the default masonry compression strength of $f_{m}^{\prime}=8 \mathrm{MPa}$, to avoid the need for carrying out prism tests. It is apparent, however, from Figures 6-8 that the required ductility will not always be available with this low strength. Consider a masonry wall of dimensions

$\mathrm{h}_{\mathrm{w}}=16 \mathrm{~m}, \mathrm{l}_{\mathrm{w}}=4 \mathrm{~m}, \mathrm{~b}_{\mathrm{w}}=0.19 \mathrm{~m}$, designed for $S=1.0$ and reinforced vertically with D16 bars at $400 \mathrm{crs}$ (i.e. $\rho=0.00264$ ). The axial load carried is $\mathrm{N}_{\mathrm{u}}=720 \mathrm{kN}$ $\left(\frac{\mathrm{u}}{\mathrm{f}_{\mathrm{m}}^{\prime} \mathrm{g}}=0.118\right)$. From Figure 6 , for $f_{y}=275 \mathrm{MPa}$, with $\rho \frac{8}{f_{m}^{\prime}}=0.00264$ (i.e. $f_{m}^{\prime}=8 \mathrm{MPa}$ ), the displacement ductility factor related to an aspect ratio of $\mathrm{A}_{\mathrm{T}}=3$ is

$\mu_{3}=2.77$, as shown.

for

From Figure 8 the correction factor

$$
\begin{aligned}
& A_{T}=\frac{16}{4}=4.0 \text { is } \\
& \frac{\mu_{4}-1}{\mu_{3}-1}=0.795
\end{aligned}
$$

Thus the available ductility for $\mathrm{f}_{\mathrm{m}}^{\prime}=8 \mathrm{MPa}$ is

$$
\mu_{4}=1+0.795(2.77-1)
$$$$
=2.41
$$

This is less than the design level of ductility required by $\mathrm{Eq}$. 1 of

$$
\mu=\frac{4}{S}=4.0 \text {. }
$$

Thus the required ductility is not available, despite the low reinforcement ratio and axial load level (0.94MPa). Three options are open to the designer:

He can recognize the limited ductility available, and redesign for a higher $S$ factor (approximately $\mathrm{S}=1.6$ in this case). However this will entail increasing the flexural reinforcement content, thus further reducing the available ductility.

(2) Confining plates could be inserted in critical mortar courses within the plastic hinge region at each end of the wall.

(3) A higher value of $f_{m}^{\prime}$ could be adopted in design, and in-situ prism tests taken to ensure the design level is obtained. For example, if $\mathrm{f}_{\mathrm{m}}^{\prime}=16 \mathrm{MPa}$, the axial load ratio becomes

$\frac{\mathrm{N}_{\mathrm{u}}}{\mathrm{f}_{\mathrm{m}}^{\prime} \mathrm{A}_{\mathrm{g}}}=0.059$

and the effective reinforcement ratio becomes

$\rho \cdot \frac{8}{f_{m}^{\prime}}=0.00132$.

From Figure 6, 


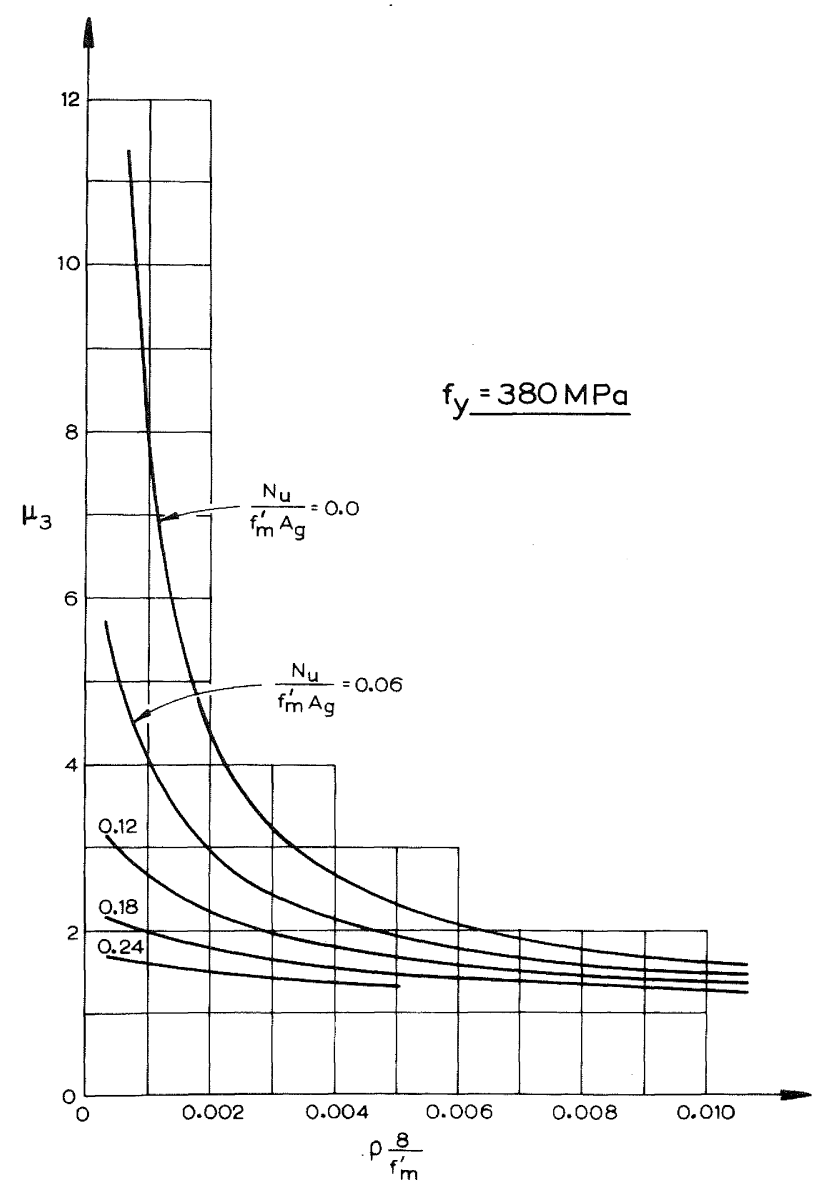

FIG. 7 - DUCTILITY OF MASONRY WALLS FOR ASPECT RATIO $A_{T}=3(f y=380 \mathrm{MPa})$

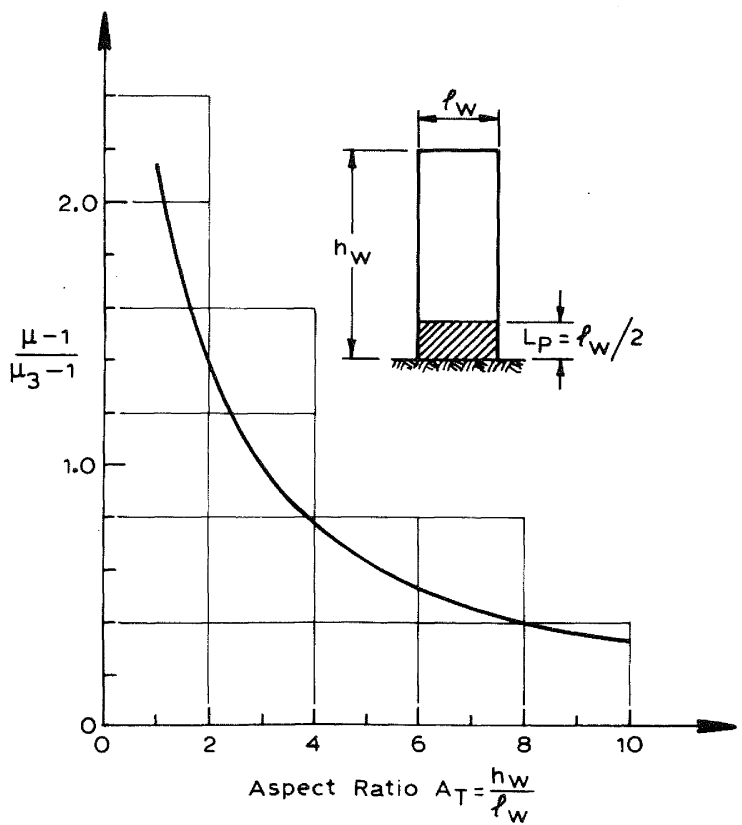

FIG. 8 - CORRECTION FACTOR FOR WALL ASPECT RATIO (Related to $A_{T}=3$ as datum) 


$$
\mu_{3}=5.5
$$

and thus

$$
\begin{aligned}
\mu_{4} & =1+0.795(5.5-1) \\
& =\underline{4.6} \text { which is adequate. }
\end{aligned}
$$

This option will be preferred where masonry of dependably high strength can be obtained. It should be noted that in prism tests using standard blocks, grout mix and mortar, prism strengths between 22 and $30 M P a$ were consistently obtained ${ }^{4}$.

The graphs presented apply only to rectangular section walls. More critical conditions may exist with flanged walls, particularly for $T$ sections where the flange is in tension. In such cases a detailed analysis should be carried out. However, an approximate value for the available ductility can be obtained by checking the ductility of an equivalent rectangular wall with dimensions equal to the web dimensions, carrying the entire $T$ section axial load, and with an equivalent reinforcement ratio

$$
\rho_{w}=\frac{\left(A s t_{w}+2 A_{f}\right)}{b_{w} l_{w}}
$$

where Ast ${ }_{w}$ is the total web steel area, $\bar{A}_{f}$ is the total flange steel area, and $b_{w}$ and $l_{w}$ are the web width and length respectively.

I-sections and T-sections with the web in compression will rarely have ductility problems.

\section{CONCLUSIONS:}

A simple method suitable for design office usage has been developed to enable available ductility of masonry shear walls of rectangular section to be checked. Results are presented in graphical form which indicate that available ductility decreases with increasing axial load, and reinforcement content and yield stress, but increases with increasing masonry crushing strength.

Where the graphs indicate that ductility capacity is less than implied by the design $S$ factor, the designer has the options of increasing the design lateral load level, and hence reducing ductility demand, using confining plates in mortar beds within the plastic hinge zones, or designing to a higher value of masonry compression strength. In many cases the last option will be the most economical.

Although the curves are developed for walls of rectangular section, they can be used to obtain approximate solutions for T-section walls where the flange is in tension. These walls are more critical than rectangular section walls.

\section{REFERENCES :}

1. 'Code of Practice for General Structural Design and Design Loadings for Buildings" NZS4 203:1976. S.A.N.Z., Wellington, 1976, $104 \mathrm{pp}$.

2. 'The Design of Reinforced Masonry' DZ4210 Part B, S.A.N.Z., Wellington, 1980 .

3. 'The Design of Concrete Structures' DZ3101, S.A.N.Z., Wellington, 1980.

4. Priestley, M.J.N., and Elder, D.M. 'Seismic Behaviour of Slender Masonry Shear Walls', Dept. of Civil Engineering, University of Canterbury, Research Report (to be published).

5. Kent, D.C., and Park, R., 'Flexural Members with Confined Concrete', Journal Structural Div. ASCE, Vol. 97, July 1971, pp.1969-1990.

6. Priestley, M.J.N., 'Seismic Design of Masonry Buildings - Background to the Draft Masonry Design Code DZ4210!. Bull. NZNSEE, Vol. 13, No. 4, Dec. 1980

7. Gill, W.D., Park, R. and Priestley, M.J.N., 'Ductility of Rectangular Reinforced Concrete Columns with Axial Load', Dept. of Civil Engineering, University of Canterbury Research Report 79-1, February 1979, 136pp.

8. Ang, B.G., Priestley, M.J.N., Park, R.,' 'Ductility of Slender Confined Concrete Columns'. Department of Civil Engineering, University of Canterbury, Research Report (to be published). 